\title{
The relationship betweens math anxiety and arithmetic reasoning: The mediating role of working memory and self-competence
}

\author{
Marija Živković ${ }^{1} \cdot$ Sandra Pellizzoni ${ }^{1}$ (D) Irene C. Mammarella ${ }^{2}$ (D ) Maria Chiara Passolunghi ${ }^{1}$ (D)
}

Accepted: 20 January 2022

(c) The Author(s) 2022

\begin{abstract}
The complex interplay between cognitive and emotional factors at the base of maths achievement started to be evaluated and quantified in the last few years. Only a few studies, anyway, examine at the same time, the role of working memory (visuospatial and verbal subsystem) and maths anxiety together with self-competence, on maths attainment. To investigate the specific link between these three factors, in a large developmental sample, we enrol 335 students from the 3rd, 5th, and 7th grades. In respect to emotional and motivational factors, data indicates a direct influence of maths anxiety on maths performance. Furthermore, the results highlight that maths anxiety differently impacts working memory subsystems. In fact, we observe a significant and indirect effect of MA, through the visuospatial system, on maths achievement. Our results provide further support to the hypothesis that maths anxiety is a special type of anxiety, most likely impacting the visuospatial rather than the verbal working memory subsystem. Data is discussed in terms of a possible mechanism underlying maths anxiety and visuospatial working memory at the base of this specificity, and in relation to the role of self-competence in this interplay.
\end{abstract}

Keywords working memory $\cdot$ maths anxiety $\cdot$ self-competence $\cdot$ arithmetic reasoning $\cdot$ primary and middle school students

Mathematic ability is one of the most crucial skills that a person needs to master in life for its well-established role at a personal level referring to salary size (Dougherty, 2003), socioeconomic status (SES) (Gerardi et al., 2013; Gross et al., 2009), properly mastering everyday activities, and personal wellbeing (Reyna et al., 2009). At a collective level, math abilities are essential to exercise aware citizen, for the economic success of Nations (Foley et al., 2017) and contrast economic inequality (Pellizzoni et al., 2020). The basic arithmetic is part of modern life and essential for different numerical-problem-solving situation, but also important for advanced mathematical skills that are important part of modern scientific disciplines (Campbell \& Xue, 2001). Zhou (2011) define mathematical reasoning as "mathematical methodology of axiomatic reasoning, logical

Maria Chiara Passolunghi

passolu@units.it

Marija Živković

https://orcid.org/0000-0003-3126-2903

1 Department of Life Science, Gaetano Kanizsa Psychology Unit, University of Trieste, Trieste, Italy

2 Department of Developmental and Social Psychology, University of Padova, Padua, Italy deduction, and formal inference." Given the importance of these abilities, it is fundamental to study and describe the factors that can promote or hinder the learning process at the base of this discipline. Previous studies have extensively investigated the cognitive abilities (intelligence, memory, processing speed) that prompt maths learning considered as general cognitive precursors (Giofrè et al., 2017). On the other hand, other studies have evaluated the contribution of the emotional factors (e.g., general or specific anxiety) on maths performance (e.g., Donolato et al., 2020). Nevertheless, only a few contributions have focused on the reciprocal influence between cognitive and emotional factors in the determination of maths proficiency, especially if referring to young children (Ramirez et al., 2013; Vukovic et al., 2013). Furthermore, researchers recognized the crucial role of motivational factors (e.g., self-competence) on maths performance. Self-competence, as a part of global self-esteem, is defined as the evaluation of a child's effectiveness in different environments and has been documented to be a mediator between anxiety and achievement in different domains (Bracken, 1992; Donolato et al., 2019).

Given the scarcity of the studies that have jointly investigated cognitive, emotional, and motivational factors in the literature, this study had the aims to: 1) jointly evaluate the 
correlation between emotional, motivational, and cognitive factors - too often investigated separately- and arithmetic reasoning in the students of the $3^{\text {rd }}, 5^{\text {th }}$, and $7^{\text {th }}$ grades. Among the others, we consider crucial to observe the possible relationship between working memory (verbal and visuospatial components) and self-competence, scarcely evaluated in other contributions; 2 ) to investigate the mediating role of working memory and self-competence to better understand the relationship between maths anxiety and arithmetic reasoning. Through examination of the both type of working memory (verbal and visuo-spatial) and self-competence as mediators the study tried to better and more in the deep understand the relationship between math anxiety and math performance the study. Important fact is that limited number of studies investigated mediating role of WM and self-competence on the relationship between math anxiety and mathematics in school age children as a unique model (Justicia-Galiano et al., 2017).

\section{Cognitive abilities and maths domains: The role of Working memory}

The general cognitive functions (e.g., intelligence and memory) include abilities on which multiple learning processes are grounded. Among them, a crucial factor is represented by working memory (WM) (De Smedt et al., 2009). This factor has a well-established effect on a variety of maths domains such as mental addition and subtraction (Mammarella et al., 2013), and problem-solving (Passolunghi et al., 2019). The most well-known WM model is a tripartite model which includes a central executive, responsible for data storage, processing, and monitoring, and another two domain-specific systems devoted to processing either verbal or visuospatial information (Baddeley \& Hitch, 1974). The episodic buffer was added as the fourth element of the model and presents the limited capacity-system that provides and integrates temporary storage of information from the longterm memory and two subsystems (Baddeley, 2000). However, the episodic buffer is rarely studied in young children and even if researchers have proposed alternative models to explain WM functioning, such as a domain-general (Kane et al., 2004) or a domain-specific (Shah \& Miyake, 1996), studies in developmental psychology indicate that the tripartite model can better explain the WM functioning (Giofrè et al., 2017).

WM has been extensively studied on variety of math domains, such as geometry (Giofrè et al., 2013; Giofrè et al., 2014), mental calculation (Passolunghi \& Siegel, 2004; Caviola et al., 2014), and problem solving (Andersson, 2007; Passolunghi et al., 2019). Also, different studies showed that children who performed poorly in WM tasks did not reach the expected levels of math performance
(Gathercole \& Pickering, 2000; Geary, 2004; Passolunghi \& Mammarella, 2010, 2012). Recently, studies have focused on an intriguing debate on modality dependent (verbal or visuospatial) stimulation of WM. Some research indicates a substantial correlation between the verbal (VWM) and visuospatial (VSWM) domains (Kane et al., 2004), while others observed this distinction in some ages, but not in others (Swanson, 2008). According to some studies, VWM is more likely to be related to reading attainment while VSWM more related to maths performance (Giofrè et al., 2018). Soltanlou et al. (2015) showed a developmental perspective in this connection: VWM was the best predictor in multiplication performance in $3^{\text {rd }}$-grade students while VSWM was the best predictor of maths performance in the $4^{\text {th }}$ grade. The previously mentioned literature indicates that it is fundamental to investigate the specific influence of VWM and VSWM according to the age and the type of task involved (Giofrè et al., 2018). In fact, a study conducted by Wong and Szücs (2013) showed that maths tasks presented in written format can inherently engage the visual components and had shown that format influences strategies that participants would choose.

\section{Influence of maths anxiety on maths performance}

Students can experience a range of different achievement emotions that are directly connected to achievement activities or achievement outcomes (Pekrun \& Perry, 2014). The previous study (Lichtenfeld et al., 2012) showed that in primary school students the most experienced emotions are enjoyment, boredom, and anxiety. In this study will be investigated the specific type of anxiety that is recognised as maths anxiety (MA): "a feeling of tension, apprehension, or fear that interferes with math performance" (Ashcraft, 2002). We were particularly interested in this emotional factor because of its well establish role on math achievement underlined by different meta-analysis report: Hembree (1990) found that MA correlates with math achievement scores in pre-college students $(\mathrm{r}=-.27)$, and in college students $(r=-.31)$ and Namkung et al. (2019) found an intensification of this negative relationship with age $(\mathrm{r}=$ -.27 for primary grades and $r=-.36$ for secondary grades). Furthermore, this specific type of anxiety is so derailing that it causes emotional tension, decreases maths enjoyment, and induces less self-confidence concerning mathematics. These feelings induce avoidant behaviours arisen by math stimuli such as: 1) drop out of maths tasks (see Ashcraft, 2002), 2) avoidance in taking maths exercises (Ashcraft, 2002), and 3) escaping from situations in which maths is requested (Ashcraft \& Krause, 2007). This type of anxiety is specifically aroused by tasks and situations involving numerals and is 
dissociated from the form of anxiety associated with general testing settings (e.g., Ashcraft, 2002). Wu et al. (2014) observed a feedback loop in the relation between mathematical achievement and anxiety: the feeling of tension provokes avoidance and negative bias regarding actual competencies, which, in turn, leads to less enjoinment in practice. The lack of experience with maths activities determines less practice and, therefore, lower self-confidence, therefore boosting the anxiety feelings.

The detrimental role of MA on performance is well established in adults and older students (reaching a peak around the 4th grade), although the effects of MA may be observed from the first years of schooling (Ramirez et al., 2013; Vukovic et al., 2013). This data shows the early roots of this connection that calls for a specific evaluation of the developmental trajectory of this phenomenon.

Does MA determine a decrease in maths performance or the scarce maths abilities affect the feelings experienced during task execution, because of repeated experiences of failure? This question raises another crucial topic. A recent conclusive contribution, including a large sample of school children (Devine et al., 2018), suggests that cognitive and emotional mathematics problems largely dissociate. In fact, if children with developmental dyscalculia were twice as likely to have high MA compared with children with typical development, $77 \%$ of children with high MA would have typical or high mathematics performance. These findings suggest to closely look at the mechanisms underlying the relationship between MA and math performance.

\section{The mediating role of WM on the relationship between MA and performance}

Extensive evidence showed that the relation between MA and WM influences math performance and to date, WM has been the most studied factor that could explain the relationship between MA and math performance. One of the theories that tried to explain the relation between MA, WM, and performance is the processing efficiency theory (PET, Eysenck \& Calvo, 1992). The PET was developed on Baddeley's model of WM and propounds the explanation that anxious thoughts (worries) influence WM by reducing WM capacity. Several studies showed the detrimental effect of MA on maths achievement by reducing the WM resources (Ashcraft \& Kirk, 2001; Beilock \& Carr, 2005). High WM abilities were proposed to have a protective role from the detrimental effects induced by anxiety. In this respect, Ashcraft and Kirk (2001) indicate that adults with higher WM could manage both maths tasks and anxiety-driven thought more successfully. More gifted WM individuals seem not to be affected by this type of connection. In particular, Miller and Bichsel (2004) observed that among the adults with high MA those with higher WM showed the best performance in calculation and problem-solving.

An alternative account proposes that individuals with high WM levels are more exposed to maths failure due to disruption caused by anxiety, especially in tasks solved under pressure. This happened presumably because of the consumption of cognitive resources otherwise devoted to the task resolution (Caviola et al., 2017a). This phenomenon labelled "choking under pressure", has been described by Beilock and Carr (2005) in a series of studies on adults who were asked to solve demanding maths problems. The results indicate that people who rely more heavily on WM when solving the maths tasks showed lower maths performance, while participants who rely less on WM were less affected by MA when solving the maths tasks. Geary et al. (2004) showed the association between MA and maths achievement, only in children with high WM capacity as an interaction of anxiety and resource that children rely on to recover fundamental facts from long-term memory and to inhibit competing answers. There is a possibility that students with high WM capacity and high levels of MA switch their problem-solving strategies because of the influence of MA on WM (Ramirez et al., 2013).

It is crucial to note, anyway, that a growing literature on the field indicates that MA negatively impacts maths performance by depressing specifically VSWM resources (Soltanlou et al., 2015, 2019; Miller \& Bichsel, 2004). The relevance of visuospatial WM in certain type of math tasks has already been shown students (Soltanlou et al., 2015), furthermore a recent study suggests that children with higher MA have less storage capacity for visual and spatial information (e.g. in solving multiplication problems, Soultanlou et al., 2019). In this sense, MA seems to play a greater role on VSWM than VWM in maths performance. Most of the studies investigated the mediating role of VWM or VSWM on the relationship between trait or state anxiety (rather than MA) and math performance (Owens et al., 2012; Ganley \& Vasilyeva, 2014), but the limited number of studies investigated the mediating role of VSWM, VWM and self-competence on the relationship between MA and math performance (Justicia-Galiano et al., 2017). Because of the gap in the literature the study tested mediating role of three different factors on the relationship between MA and math performance as a unique model.

\section{Influence of self-competence on math performance}

Math performance is also influenced by different motivational factors, in the literature defined as self-efficacy (Bandura, 1986), self-esteem (Bracken, 1992), and ego-resilience 
(Donolato et al., 2020 ) In this study will be investigated a part of self-esteem construct defined as school self-competence because of its high level of reliability and its well established correlation with achievement (Eccles et al., 1998). A comprehensive theoretical model of the motivational and social influences on students' engagement and performance in mathematics was proposed by Eccles, Eccles et al. (1998). Model underline two sets of beliefs linked to achievement-related choices: the individual's expectations for success ("Can I do the task?") and the importance of the various options perceived by the individual as available ("Do I want to do the task?"). In fact, Eccles et al. (1998) showed a mediating role of self-competence in the achievement of different domains. Some authors reported that students who believe that they can solve the task that is in front of them showed better performance and higher motivation (Bandura et al., 1994). Self-competence is strongly correlated with successful learning and can also influence personal development and well-being. Students with positive beliefs about their mathematical knowledge will be highly engaged in maths activities. On the contrary, students with negative beliefs about maths will avoid maths activities, which means less maths practice and higher MA (Dowker et al., 2012; Ramirez et al., 2013). This tendency is present from early stages and a study (Clerkin \& Gilligan, 2018) showed a significant positive relation between early numeracy and children's confidence towards maths. A longitudinal study that investigated the predictive role of cognitive (WM and intelligence) and motivational factors (self-perceived abilities and intrinsic values) on maths and German language in fourth-grade students, showed that cognitive factors are stronger predictors, but for the German language, motivational factors showed a stronger influence (Weber et al., 2013). Dowker et al. (2012) showed that children who selfrated themselves as higher performers are better in maths. These are the results that confirmed the positive relation between positive maths beliefs and maths performance in a way that children who believe more in their capacity to solve maths problems performed better in maths.

\section{The present study}

In the present study we examined the role of working memory (visuospatial and verbal subsystem) and MA together with self-competence, on arithmetic reasoning, and we tried to reach the following aims:

1. jointly evaluate the correlation between emotional, motivational, and cognitive factors - too often investigated separately- and arithmetic reasoning in the students of the $3^{\text {rd }}, 5^{\text {th }}$, and $7^{\text {th }}$ grades and, among the others, to observe the possible relationship between working memory (verbal and visuospatial components) and selfcompetence,

2. to investigate the mediating role of WM and self-competence to better understand the relationship between MA and arithmetic reasoning.

We hypothesized that VSWM, but not VWM, had a more salient role in the interplay between MA and arithmetic reasoning, being particularly impaired by anxiety (Miller \& Bichsel, 2004; Vukovic et al., 2013). Miller and Bichsel (2004) indicated how MA appears to primarily impact the visual component, and Vukovic et al. (2013) showed that MA was negatively correlated with math achievement. Also, it was analysed the relationship between WM and selfcompetence with the hypothesis that the more a child has a positive self-competence, the higher the score on VWM will be (Donolato et al., 2019; Justicia-Galiano et al., 2017).

We expected the direct influence of VWM, VSWM, MA, and self-competence on arithmetic reasoning (Donolato et al., 2019), and an indirect influence of MA on arithmetic reasoning through the measures of VWM, VSWM, and self-competence (Justicia-Galiano et al., 2017). Donolato et al. (2019) examined influence of WM, anxiety, depressive symptoms and personal assets on mathematics and reading literacy in middle school students. This study showed positive influence of personal assets (ego-resiliency, selfconcept, academic and competence dimensions) on both subjects. Also, negative affect (anxiety and depressive symptoms) showed important influence on subjects in middle school students. On the other side, Justicia-Galiano et al. (2017) investigated mediating role of working memory and math self-concept in the relationship between MA and math performance in sample of students between 8 and 12 years old. The study confirmed that both mediators have important role in the relationship between MA and math performance.

To reach these aims students were assessed in two phases: during the first phase at the beginning of the school year, cognitive (VWM and VSWM), emotional (MA), and motivational factors (self-competence) were tested. In the second phase, 5 months later, their maths ability was tested. We explored the reciprocal relation between the variables of interest (i.e., MA, self-competence, VWM, VSWM, and maths achievement) by using path analysis models.

\section{Method}

\section{Participants}

The research has been carried out in seven different primary and two middle schools from the North-East part of Italy. There were 335 students who participated in the study (168 males and 167 females; $123-3^{\text {rd }}$ graders, $109-5^{\text {th }}$ graders, 
and $103-7^{\text {th }}$ graders) with $\mathrm{M}_{\text {age }}(\mathrm{SD})=10.54$ (1.72). All participating students were Caucasian, the SES of the sample was primarily middle class as established by the school records. A written informed consent form following the Declaration of Helsinki was signed by the student's parents and the school's principals. This study was conducted following the ethical guidelines of the Italian Association of Psychology and the ethical code of the Italian Register of Professional Psychologists.

\section{Materials}

\section{Cognitive factors}

\section{Verbal working memory}

The Digit span (Wechsler, 2003, Italian version adapted by Orsini et al., 2012) presents one of the subscales of WISC IV where to the participant was read a sequence of numbers and asked to repeat the same sequence back to the examiner in order (forward span) or reverse order (backward span). There are two sets per trial, starting with two digits and going up to a maximum of nine digits. The test is interrupted when the child has repeated all the sequences or when he or she gets all the items in the sequence wrong. The total raw score for the test is obtained by awarding 1 point for each correct answer and 0 for each wrong answer. The sum of the raw scores was converted into a scaled score using the specific conversion table.

\section{Visuospatial working memory}

The Dot Memory task (derived by Miyake et al., 2001, Italian version adapted by Mammarella et al., 2008). A computerized version of the task was used. In the subtest Dot Memory participants were asked to: 1) remember the location of two Xs that appear inside of a matrix, and 2) when the empty matrix reappears participants need to indicate the position of the $\mathrm{X}$ inside of the empty matrix. The result presents the number of the $\mathrm{X}$ positions correctly recalled by the participant.

\section{Non-cognitive factors}

\section{Maths anxiety}

The Abbreviated Math Anxiety Scale (AMAS, Hopko et al., 2003, Italian version adapted by Caviola et al., 2017b) is a self-report questionnaire with 9 items adapted to primary school students. This questionnaire is using a 5-point Likert scale where participants indicate how much anxiety they would feel in the situation that involved maths (e.g., $1=$ low anxiety, $5=$ high anxiety). The scale is divided in two subscales measuring Math Learning Anxiety (5 items) and Math Testing Anxiety (4 items). The total score was the sum of all scores for each item, with a higher score corresponding to a higher level of MA.

\section{Self-competence}

The Multidimensional Self-Concept Scale (Bracken, 1992, Italian version) is a self-report scale for the assessment of self-concept in children and adolescents. This scale has six different subscales: Social, Competence, Affect, Academic, Family, and Physical. For the present study, we used subscale Competence (SC-C) to assess how participants perceived their ability to influence their environment, solve problems, or achieve their goals, respectively. The subscale consists of 25 statements scored on a 4-point Likert scale from 1 ("absolutely false") to 4 ("absolutely true"), higher scores indicate a more positive self-perception. Here, are reported some examples of items: "I am not as good as I should be" and "I am not very smart". To obtain the standard score of the subscale, the raw score is calculated and transformed into the total score using a specific conversion table, the total score with the specific conversion table will be transformed into the standard score. The standard score was used as a final score for this measure.

\section{Arithmetic reasoning}

The test that evaluates calculation skills and problem-solving (AC-MT 3, Cornoldi et al., 2020) was used to measure arithmetic reasoning, two paper-and-pencil subtests: Matrix reasoning and Inferences. Subtest Matrix reasoning assesses the ability to correctly reasoning about the properties of numerical series. Participants have to complete an incomplete numerical matrix with the correct number. For every grade has 12 assignments and one minute for subtest to be solved. Inferences investigate the ability to perform inferential mathematical reasoning, understanding of mathematical symbols, the degree of automation procedures, and fundamental principles of arithmetic. The subtest is divided into three different types of tasks: the first task requires operation performance with figures, in the second task, operations presented in Arabic format with the missing sign $(+,-, \times,:)$ have to be completed, and in the third task there are pairs of operations, one incomplete and the other one similar already turned to the side. Participants are asked to resolve the first incomplete operation, not by doing the calculations, but by helping with the second operation already carried out, which offers a clue to the resolution of the first one. The subtest for third graders has 12 assignments that need to be solved in 2 minutes and 30 seconds. The subtest for fourth and fifth-grade students has 12 assignments: for the first task 
Table 1 Descriptive Statistics of all variables by grade

\begin{tabular}{lllllll}
\hline & $3^{\text {rd }}$ & $5^{\text {th }}$ & $7^{\text {th }}$ & Minimum & Maximum & Reliability \\
\hline $\mathrm{N}$ & 123 & 109 & 103 & & & \\
Age & 8.62 & 10.79 & 12.58 & 8 & 13 & \\
VWM & $11.11(3.17)$ & $11.02(3.15)$ & $12.51(4.64)$ & 1 & 30 & .85 \\
VSWM & $-.51(.56)$ & $.03(.96)$ & $.56(1.12)$ & -1.22 & 3.70 & .85 \\
MA & $23.21(8.76)$ & $23.29(7.32)$ & $21.77(6.37)$ & 9 & 44 & .83 \\
Self-Competence & $52.63(15.25)$ & $48.90(15.20)$ & $47.25(10.43)$ & 0 & 97 & .78 \\
AR & $-1.01(2.10)$ & $-.19(2.38)$ & $2.69(2.53)$ & -5.53 & 8.04 & .80 \\
\hline
\end{tabular}

VWM -verbal WM, VSWM - visuospatial WM, MA-math anxiety, AR- arithmetic reasoning participants have a minute and for the second and the third task one minute. Both subtests have a time limitation. Each correct answer scored one point, and wrong answers scored zero. The sum of all answers presents the raw score that was transformed into a scaled score using a specific conversion table for each grade. The sum of both subscales was used as a final score.

\section{Analytic strategies}

SPSS IBM 21 was used to obtain the descriptive, correlation, and hierarchical regression analyses between all measures. We conducted a bivariate correlation analysis using Pearson $r$ between arithmetic reasoning, cognitive (VWM and VSWM), emotional (MA) and motivational factors (selfcompetence) for the whole sample. Hierarchical regression analyses were conducted to investigate the influence of VWM, VSWM, MA, and self-competence on arithmetic reasoning.

To explore our main research question the reciprocal relation between the variables of interest (i.e., MA, selfcompetence, VWM, VSWM, and arithmetic reasoning) as our second hypothesis, path analyses were done with the lavaan package (Rosseel, 2012) for R (R Core Team, 2019).

\section{Results}

The descriptive statistics split by grade and reliability for all measures are reported in Table 1.

Bivariate correlations between arithmetic reasoning, cognitive (VWM and VSWM), emotional (MA), and motivational factors (self-competence) are presented in the Table 2.

To analyze how cognitive (VWM and VSWM), emotional (MA), and motivational factors (self-competence) can predict arithmetic reasoning, a hierarchical regression analysis has been carried out. Arithmetic reasoning was inserted as a dependent variable and the independent variables are in the first block measures VWM (Digit span), in the second block measure VSWM (Dot Memory), in the third block measure
Table 2 Zero-Order Correlations Between All Measures

\begin{tabular}{llllll}
\hline & 1 & 2 & 3 & 4 & 5 \\
\hline 1. VWM & - & & & & \\
2. VSWM & $.153^{* *}$ & & & & \\
3. MA & -.107 & $-.169 * *$ & - & & \\
4. SC & $.142 * *$ & .014 & $-.223 * *$ & - & \\
$5 . \mathrm{AR}$ & $.223 * *$ & $.381^{* *}$ & $-.224 * *$ & -.103 & - \\
\hline
\end{tabular}

VWM - verbal WM, VSWM - visuospatial WM, MA - Math anxiety, $\mathrm{SC}$ - Self-competence, AR- Arithmetic reasoning

$* \mathrm{p}<.05 ; * * \mathrm{p}<.01$

Table 3 Hierarchical regression analysis

\begin{tabular}{llllll}
\hline $\begin{array}{l}\text { Independent vari- } \\
\text { ables (blocks) }\end{array}$ & $\mathrm{R}^{2}$ & $\Delta \mathrm{R}^{2}$ & Sig. & $\beta$ & $\mathrm{p}$ \\
\hline 1. VWM & .049 & .049 & .001 & .222 & .001 \\
2. VWM & .180 & .131 & .001 & .162 & .002 \\
VSWM & & & & .366 & .001 \\
3. VWM & .204 & .024 & .001 & .148 & .004 \\
VSWM & & & & .343 & .001 \\
MA & & & & -.159 & .002 \\
4. VWM & .234 & .030 & .001 & .169 & .001 \\
VSWM & & & & .336 & .001 \\
MA & & & & -.199 & .001 \\
SC & & & & -.178 & .001 \\
\hline
\end{tabular}

VWM - verbal WM, VSWM - visuospatial WM, MA - Math anxiety, SC - Self-competence

for MA (AMAS), and in the fourth block self-competence (TMA-Competence).

The model explains in total $23 \%$ of the variance of the performance in arithmetical reasoning. Hierarchical linear regression showed significant influence of measures for $\operatorname{VWM}\left(\Delta R^{2}=.049, p=.001\right), \operatorname{VSWM}\left(\Delta R^{2}=.131, p=\right.$ $.001)$, MA $\left(\Delta R^{2}=.024, p=.001\right)$, and self-competence $\left(\Delta R^{2}=.030, p=.001\right)$ on arithmetical reasoning (see Table 3).

After regression analysis path analysis was run for testing both direct and indirect effect, to show the effect of MA 
on arithmetic reasoning mediated by VWM, VSWM and self-competence. We ran a path analysis and tested model fit considering: the chi-square $(\chi 2)$, the comparative fit index (CFI), the normed fit index (NFI), the Tucker fit index (TFI), and the root mean square error of approximation (RMSEA); the chi-square difference $(\Delta \chi 2)$, and the Akaike information criterion (AIC) were also used to compare the fit of alternative models (Kline, 2011). For the proposed of analysis, MA was considered as independent variable, arithmetic reasoning as dependent variable, and VSWM, VWM, and self-competence as mediator variables. Model statistical fit was good: $\mathrm{CMIN}=4.76, d f=2, \mathrm{CMIN} / d f=2.38, p=.09$, $\mathrm{CFI}=.977, \mathrm{NFI}=.963, \mathrm{TLI}=.885, \mathrm{RMSEA}=.065, \mathrm{AIC}$ $=6830.548, \mathrm{BIC}=6875.954$. Results showed Arithmetic Reasoning to be significantly predicted by Digit span $(\beta=$ $.17 ; p=.001)$, Dot memory $(\beta=.34 ; p=.000)$ directly and positively, and negatively by Self-competence ( $\beta=-.20 ; p$ $=.000)$ and Math anxiety $(\beta=-.18 ; p=.000)$. The analysis also showed indirect, significant and negative impact on Arithmetic Reasoning by Math anxiety through measure of Dot Memory $(p=.006)$ and Self-competence $(p=.006)$. Analysis showed significant path between Digit span and $M A(\beta=-.11 ; p=.040)$, Dot memory and $M A(\beta=-.16$; $p=.003)$ and between Self-competence and $M A(\beta=-.23$; $p=.000)$. The percentage of explained variance $\left(R^{2}\right) .24$. (See Figure 1)

\section{Discussion}

Mathematical skills are essential to guide personal and professional choices, master everyday activities, and effectively exercise citizenship in a complex society. Given the relevance of this acquisition and the complex interplay between cognitive, emotional and motivational factors on maths performance, we investigated: 1) the correlation between WM components, MA, self-competence, crucial for arithmetic reasoning, but rarely jointly evaluated; 2) the mediating role of VWM, VSWM and self-competence in the relation between MA and arithmetic reasoning extending and completing a recent study (Justicia-Galiano et al., 2017; Soltanlou et al., 2015); 3) the correlation between VWM, VSWM, and self-competence, not fully investigated in previous studies (Donolato et al., 2019; Justicia-Galiano et al., 2017).

The present study ameliorates the assessment of MA and WM in several ways: first of all, we evaluated with reliable measures both VWM and VSWM in the attempt to disambiguate the specific role of both WM components on maths achievement and MA (Vukovic et al., 2013) and, secondly, we use a reliable and well-known scale to measure MA -Abbreviated Math Anxiety Scale- (Hopko et al., 2003).

Concerning the first objective our data showed a significant and positive influence of VWM and VSWM on arithmetic reasoning and a negative and significant correlation between MA and arithmetic reasoning. Furthermore, a negative and significant correlation between MA and VSWM was observed but no significant correlation between MA and VWM emerged. Hierarchical regression analysis showed further detail of the relation between visuospatial and verbal components on arithmetic reasoning: VSWM had the strongest influence on arithmetic reasoning. Previous studies that investigated the relationship between MA and WM subcomponents showed mixed results. Some research used only the measure for VWM (Digit, Word or Listening span) showing a significant correlation between VWM and MA (Ramirez et al., 2013; Justicia-Galiano et al., 2017), possibly due to the absence of VSWM measure in the design of the studies. One study used only the measure for VSWM (Swanson Cognitive Processing Test (S-CPT) visual matrix subtest, Vukovic et al., 2013) showing an early effect of MA on this component of WM. The studies that jointly evaluate VWM and VSWM are rare. One of these researche, with a

Fig. 1 Path analysis

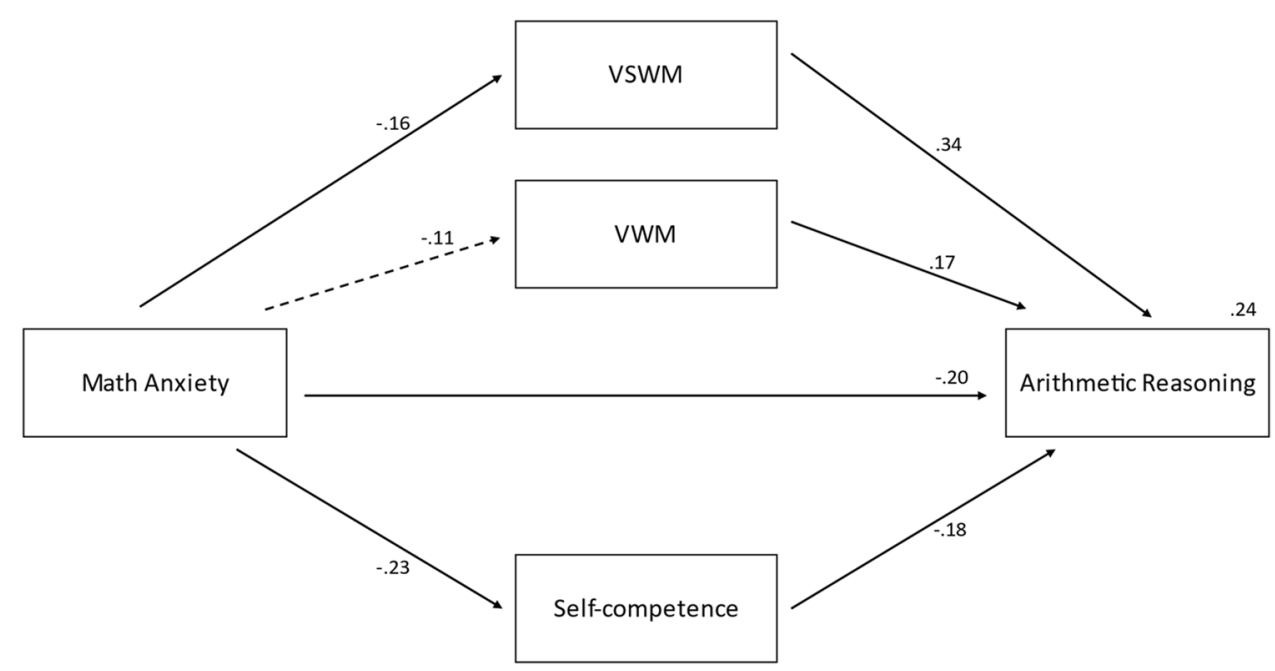


developmental sample, was designed using the Letter span test as a measure for VWM abilities and the Corsi block tapping test for VSWM components. The authors showed the specific impact of anxiety only on VSWM (Soltanlou et al., 2019), but not on VWM. On the other hand, another study indicated a non-significant correlation between MA and VWM (Backward word and Backward digit recall) and between MA and VSWM (Path dual task) (Cargnelutti et al., 2017)

Several studies, therefore, seem to point to a critical role of VSWM and MA on arithmetic reasoning as indicated in the model proposed by Miller and Bichsel (2004). The authors, in fact, showed how MA appears to primarily impact the visual component (e.g., Soltanlou et al., 2019). This tendency seems to be present also from a developmental perspective. Ramirez et al. (2013), and Vukovic et al. (2013) observed a specific impact of MA on VSWM from the very start of formal education. Our data has given further support to the previously mentioned studies (Miller \& Bichsel, 2004; Ramirez et al., 2013; Vukovic et al., 2013) completing and enriching their perspective. The study observed the relationship between VWM, VSWM, and self-competence, which was not fully investigated in a previous study (Justicia-Galiano et al., 2017). The correlation analyses showed a significant relation between VWM and self-competence confirming the previous result, but not between VSWM and self-competence and this relationship was rarely investigated in the past. One of the explanations for this significant relationship between measures of VWM and self-competence could be seen in a stronger student's familiarity with a task that requires to remember a string of numbers, rather than self-evaluate the location of a symbol on a grid (Weber et al., 2013).

To evaluate the second objective, a path analysis was used to evaluate the direct and indirect role of WM (VWM and VSWM), MA, and self-competence on arithmetic reasoning MA had a significant indirect effect through the measure of VSWM (Dot Memory), but not through the measure of VWM (Digit span). This data seems to support previous work that underlines the impact on maths performance by depressing specifically VSWM resources (Miller \& Bichsel, 2004; Soltanlou et al., 2015, 2019) and studies that confirmed the stronger influence of "paper-and-pencil" format of maths task on VSWM compared with VWM (Wong \& Szücs, 2013). The stronger effect of MA on VSWM possibly lies in the relevance of visuospatial components involved in both these factors (Ashcraft \& Kirk, 2001), and in the type of math evaluation proposed to the children, "paper-and-pencil" format of maths task relay more on VSWM compared with VWM (Wong \& Szücs, 2013).

Another interesting result of our study concerns the mediating role of self-competence on the relationship between MA and arithmetic reasoning. Specifically, as suggested by the social-cognitive theory of Bandura (1986) the self-competence has a mediation role in the research that investigated different influences on academic performance.

Consequently, this is one of the reasons why we decided to investigate together with VWM and VSWM the direct and indirect role of self-competence in the relationship mentioned above. Our results are consistent with the PET theory (Ashcraft \& Kirk, 2001; Eysenck \& Calvo, 1992). According to these approaches, in fact, higher MA children would display more worrying and thoughts about their own self-competence which, in turn, would detract some of the VSWM resources necessary to successfully perform the tasks. In this respect, children have to increase their cognitive effort in order to compensate for their fewer resources but in certain circumstances children might not be willing to put in the extra effort required to succeed in the task. Our results are, also, in line with the study that longitudinally investigates the predictive role of cognitive and motivational factors in maths and the German language (Weber et al., 2013). The results showed cognitive factors as stronger predictors for maths performance and motivation factors as stronger predictors for the German language. In our study, the strongest predictor of arithmetic reasoning was a measure for VSWM as previous studies confirmed (Casey et al., 1995; Geary et al., 2000; Delgado \& Prieto, 2004; Mix et al., 2016). The study of Justicia - Galiano and colleagues (2017) investigated the mediating role of WM and math self-concept in the relation between MA and math performance in $3^{\text {rd }}$ and $5^{\text {th }}$ grade students. The results confirmed mediational mechanism of WM and math self-concept in the relation between MA and math performance and suggested that high math anxious children may believe that they are not capable to perform math tasks. In other words, their results suggested that MA and worry thoughts reduce math self-concept. Differently, Donolato et al. (2020) showed a positive effect of ego-resiliency on math performance and confirmed that ego-resiliency can be a protective factor for child's math achievement. The study suggested that higher levels of ego-resiliency improve a child's ability to manage general anxiety, which reduces MA and test anxiety. In agreement with Justicia - Galiano and colleagues (2017) in our study self-competence that does not act as a protective factor, but on the contrary is depressed by anxiety and therefore negatively affects arithmetic reasoning. MA causes confusion and decreases the sense of competence loading our cognitive system also with intrusive thoughts ("I am not capable; I will never be able to do the task").

Our study also reveals some limitations: firstly, future studies should better analyse the influence of more complex measures of VWM and their relationship with emotional factors and arithmetic reasoning. It is worth noting that in our study our VWM measure was not a dual task. Secondly, we did not use as a control, a measure of general 
anxiety. Even acknowledging these limitations, we think that the study has the strength to have considered selfcompetence, which did not show to act as a protective factor in mediating the relation between MA and arithmetic reasoning in the $3^{\text {rd }}, 5^{\text {th }}$, and $7^{\text {th }}$-grade students.

In conclusion, the present study confirmed a negative effect of MA on arithmetic reasoning (Barroso et al., 2020). The results showed the direct influence of cognitive factors (VWM and VSWM) (Mammarella et al., 2013), MA (Cargnelutti et al., 2017; Ramirez et al., 2013), and self-competence (Eccles et al., 1998) and underline the significant, indirect influence of MA through the measure of VSWM and self-competence on arithmetic reasoning.

Our results suggest the importance of developing novel school setting that could contain or prevent stress and worry related to math contents, sustaining cognitive and motivational aspects related to this type of learning. A possible implication of this finding is to promote training aimed at improving skills related to self- efficacy and underlining awareness of meta-cognition process (Passolunghi et al., 2020). This result could be driven by a decrease stress on the importance of the learning domain and a focus on strengthening student's autonomy and control appraisals, giving them precise goals and expectations to facilitate learning process (Hulleman et al., 2016; Pekrun, 2006).

Acknowledgments Financial support for this study was provided by a grant from the Beneficentia Stiftung to Maria Chiara Passolunghi

Data availability statement The datasets generated during and/or analysed during the current study are available from the corresponding author on reasonable request.

Open Access This article is licensed under a Creative Commons Attribution 4.0 International License, which permits use, sharing, adaptation, distribution and reproduction in any medium or format, as long as you give appropriate credit to the original author(s) and the source, provide a link to the Creative Commons licence, and indicate if changes were made. The images or other third party material in this article are included in the article's Creative Commons licence, unless indicated otherwise in a credit line to the material. If material is not included in the article's Creative Commons licence and your intended use is not permitted by statutory regulation or exceeds the permitted use, you will need to obtain permission directly from the copyright holder. To view a copy of this licence, visit http://creativecommons.org/licenses/by/4.0/.

\section{References}

Andersson, U. (2007). The contribution of working memory to children's mathematical word problem solving. Applied Cognitive Psychology: The Official Journal of the Society for Applied Research in Memory and Cognition, 21(9), 1201-1216.
Ashcraft, M. H. (2002). Math anxiety: Personal, educational, and cognitive consequences. Current directions in psychological science, 11(5), 181-185. https://doi.org/10.1111/1467-8721.00196

Ashcraft, M. H., \& Kirk, E. P. (2001). The relationships among working memory, math anxiety, and performance. Journal of experimental psychology: General, 130(2), 224. https://doi.org/10. 1037//0096-3445.130.2.224

Ashcraft, M. H., \& Krause, J. A. (2007). Working memory, math performance, and math anxiety. Psychonomic bulletin \& review, 14(2), 243-248. https://doi.org/10.3758/BF03194059

Baddeley, A. (2000). The episodic buffer: a new component of working memory? Trends in cognitive sciences, 4(11), 417-423. https:// doi.org/10.1016/S1364-6613(00)01538-2

Baddeley, A. D., \& Hitch, G. (1974). Working memory. In Psychology of learning and motivation (Vol. 8, pp. 47-89). Academic press. https://doi.org/10.1016/S0079-7421(08)60452-1

Bandura, A. (1986). Fearful expectations and avoidant actions as coeffects of perceived self-inefficacy. American Psychologist, 41(12), 1389-1391. https://doi.org/10.1037/0003-066X.41.12.1389

Bandura, A., Rumsey, M., Walker, C., \& Harris, J. (1994). Regulative function of perceived self-efficacy. In M. G. Rumsey, C. B. Walker, \& J. H. Harris (Eds.), Personnel selection and classification (pp. 261-271). Lawrence Erlbaum Associates.

Barroso, C., Ganley, C. M., McGraw, A. L., Geer, E. A., Hart, S. A., \& Daucourt, M. C. (2020). A meta-analysis of the relation between math anxiety and math achievement. Psychological Bulletin. https://doi.org/10.1037/bul0000307

Beilock, S. L., \& Carr, T. H. (2005). When high-powered people fail: Working memory and "choking under pressure" in math. Psychological science, 16(2), 101-105. https://doi.org/10.1111/j.09567976.2005.00789.x

Bracken, B. A. (1992). Multidimensional self concept scale. Pro-ed.

Campbell, J. I., \& Xue, Q. (2001). Cognitive arithmetic across cultures. Journal of experimental psychology: General, 130(2), 299.

Cargnelutti, E., Tomasetto, C., \& Passolunghi, M. C. (2017). The interplay between affective and cognitive factors in shaping early proficiency in mathematics. Trends in neuroscience and education, 8, 28-36. https://doi.org/10.1016/j.tine.2017.10.002

Casey, M. B., Nuttall, R., Pezaris, E., \& Benbow, C. P. (1995). The influence of spatial ability on gender differences in mathematics college entrance test scores across diverse samples. Developmental psychology, 31(4), 697.

Caviola, S., Carey, E., Mammarella, I. C., \& Szucs, D. (2017a). Stress, time pressure, strategy selection and math anxiety in mathematics: A review of the literature. Frontiers in psychology, 8, 1488. https://doi.org/10.3389/fpsyg.2017.01488

Caviola, S., Mammarella, I. C., Lucangeli, D., \& Cornoldi, C. (2014). Working memory and domain-specific precursors predicting success in learning written subtraction problems. Learning and Individual Differences, 36, 92-100. https://doi.org/10.1016/j.lindif. 2014.10.010

Caviola, S., Primi, C., Chiesi, F., \& Mammarella, I. C. (2017b). Psychometric properties of the Abbreviated Math Anxiety Scale (AMAS) in Italian primary school children. Learning and Individual Differences, 55, 174-182. https://doi.org/10.1016/j.lindif. 2017.03.006

Clerkin, A., \& Gilligan, K. (2018). Pre-school numeracy play as a predictor of children's attitudes towards mathematics at age 10 . Journal of Early Childhood Research, 16(3), 319-334. https://doi. org/10.1177/1476718X18762238

Cornoldi, C., Mammarella, I. C., \& Caviola, S. (2020). AC-MT-3. Test di valutazione delle abilità di calcolo e del ragionamento matematico. Edizioni Erickson. https://www.erickson.it/it/acmt3614-anni-prove-per-la-clinica

De Smedt, B., Janssen, R., Bouwens, K., Verschaffel, L., Boets, B., \& Ghesquière, P. (2009). Working memory and individual 
differences in mathematics achievement: A longitudinal study from first grade to second grade. Journal of experimental child psychology, 103(2), 186-201. https://doi.org/10.1016/j.jecp.2009. 01.004

Delgado, A. R., \& Prieto, G. (2004). Cognitive mediators and sexrelated differences in mathematics. Intelligence, 32(1), 25-32.

Devine, A., Hill, F., Carey, E., \& Szucs, D. (2018). Cognitive and emotional math problems largely dissociate: Prevalence of developmental dyscalculia and mathematics anxiety. Journal of Educational Psychology, 110(3), 431-444. https://doi.org/10.1037/ edu0000222

Donolato, E., Giofrè, D., \& Mammarella, I. C. (2019). Working memory, negative affect and personal assets: How do they relate to mathematics and reading literacy? PloS one, 14(6), e0218921. https://doi.org/10.1371/journal.pone.0218921

Donolato, E., Toffalini, E., Giofrè, D., Caviola, S., \& Mammarella, I. C. (2020). Going Beyond Mathematics Anxiety in Primary and Middle School Students: The Role of Ego-Resiliency in Mathematics. Mind, Brain, and Education, 14(3), 255-266. https:// doi.org/10.1111/mbe. 12251

Dougherty, C. (2003). Numeracy, literacy and earnings: evidence from the National Longitudinal Survey of Youth. Economics of Education Review, 22(5), 511-521. https://doi.org/10.1016/ S0272-7757(03)00040-2.

Dowker, A., Bennett, K., \& Smith, L. (2012). Attitudes to mathematics in primary school children. Child Development Research, 2012. https://doi.org/10.1155/2012/124939

Eccles, J. S., Wigfield, A., \& Schiefele, U. (1998). Motivation to succeed. In W. Damon \& N. Eisenberg (Ed.), Handbook of child psychology: Social, emotional, and personality development ( $\mathrm{p}$. 1017-1095). John Wiley \& Sons, Inc.

Eysenck, M. W., \& Calvo, M. G. (1992). Anxiety and performance: The processing efficiency theory. Cognition \& emotion, 6(6), 409-434. https://doi.org/10.1080/02699939208409696

Foley, A. E., Herts, J. B., Borgonovi, F., Guerriero, S., Levine, S. C., \& Beilock, S. L. (2017). The math anxiety-performance link: A global phenomenon. Current Directions in Psychological Science, 26(1), 52-58. https://doi.org/10.1177/0963721416672463

Ganley, C. M., \& Vasilyeva, M. (2014). The role of anxiety and working memory in gender differences in mathematics. Journal of Educational Psychology, 106(1), 105-120. https://doi.org/10. 1037/a0034099

Gathercole, S. E., \& Pickering, S. J. (2000). Working memory deficits in children with low achievements in the national curriculum at 7 years of age. British Journal of Educational Psychology, 70(2), 177-194. https://doi.org/10.1348/000709900158047

Geary, D. C., Hoard, M. K., Byrd-Craven, J., \& DeSoto, M. C. (2004). Strategy choices in simple and complex addition: Contributions of working memory and counting knowledge for children with mathematical disability. Journal of experimental child psychology, 88(2), 121-151. https://doi.org/10.1016/j.jecp.2004.03.002

Geary, D. C., Saults, S. J., Liu, F., \& Hoard, M. K. (2000). Sex differences in spatial cognition, computational fluency, and arithmetical reasoning. Journal of Experimental child psychology, 77(4), 337-353.

Geary, D. C. (2004). Mathematics and Learning Disabilities. Journal of Learning Disabilities., 37(1), 4-15. https://doi.org/10.1177/00222 194040370010201

Gerardi, K., Goette, L., \& Meier, S. (2013). Numerical ability predicts mortgage default. Proceedings of the National Academy of Sciences, 110(28), 11267-11271. https://doi.org/10.1073/pnas.12205 68110

Giofrè, D., Borella, E., \& Mammarella, I. C. (2017). The relationship between intelligence, working memory, academic self-esteem, and academic achievement. Journal of Cognitive Psychology, 29(6), 731-747. https://doi.org/10.1080/20445911.2017.1310110
Giofrè, D., Donolato, E., \& Mammarella, I. C. (2018). The differential role of verbal and visuospatial working memory in mathematics and reading. Trends in neuroscience and education, 12, 1-6. https://doi.org/10.1016/j.tine.2018.07.001

Giofrè, D., Mammarella, I. C., \& Cornoldi, C. (2014). The relationship among geometry, working memory, and intelligence in children. Journal of Experimental Child Psychology, 123, 112-128. https:// doi.org/10.1016/j.jecp.2014.01.002

Giofrè, D., Mammarella, I. C., Ronconi, L., \& Cornoldi, C. (2013). Visuospatial working memory in intuitive geometry, and in academic achievement in geometry. Learning and Individual Differences, 23, 114-122. https://doi.org/10.1016/j.lindif.2012.09.012

Gross, J., Hudson, C., \& Price, D. (2009). The long term costs of numeracy difficulties. Every child a chance trust and KPMG. National Numeracy.

Hembree, R. (1990). The nature, effects, and relief of mathematics anxiety. Journal for Research In Mathematics Education, 21(1), 33-46. https://www.jstor.org/stable/749455

Hopko, D. R., Mahadevan, R., Bare, R. L., \& Hunt, M. K. (2003). The abbreviated math anxiety scale (AMAS) construction, validity, and reliability. Assessment, 10(2), 178-182. https://doi.org/10. 1177/1073191103010002008

Hulleman, C. S., Barron, K. E., Kosovich, J. J., \& Lazowski, R. A. (2016). Student motivation: Current theories, constructs, and interventions within an expectancy-value framework. In Psychosocial skills and school systems in the 21st century (pp. 241-278). Springer, Cham

Justicia-Galiano, M. J., Martín-Puga, M. E., Linares, R., \& Pelegrina, S. (2017). Math anxiety and math performance in children: The mediating roles of working memory and math self-concept. British Journal of Educational Psychology, 87(4), 573-589. https:// doi.org/10.1111/bjep. 12165

Kane, M. J., Hambrick, D. Z., Tuholski, S. W., Wilhelm, O., Payne, T. W., \& Engle, R. W. (2004). The Generality of Working Memory Capacity: A Latent-Variable Approach to Verbal and Visuospatial Memory Span and Reasoning. Journal of Experimental Psychology: General, 133(2), 189-217. https://doi.org/10.1037/00963445.133.2.189

Kline, R. B. (2011). Convergence of structural equation modeling and multilevel modeling. https://dx.doi.org/10.4135/9781446268261. n31

Lichtenfeld, S., Pekrun, R., Stupnisky, R. H., Reiss, K., \& Murayama, K. (2012). Measuring students' emotions in the early years: the achievement emotions questionnaire-elementary school (AEQES). Learning and Individual differences, 22(2), 190-201. https:// doi.org/10.1016/j.lindif.2011.04.009

Mammarella, I. C., Caviola, S., Cornoldi, C., \& Lucangeli, D. (2013). Mental additions and verbal-domain interference in children with developmental dyscalculia. Research in Developmental Disabilities, 34(9), 2845-2855. https://doi.org/10.1016/j.ridd.2013.05.044

Mammarella, I. C., Toso, C., Pazzaglia, F., \& Cornoldi, C. (2008). BVSCorsi. Batteria per la valutazione della memoria visiva e spaziale. Con CD-ROM. Edizioni Erickson. https://www.erickson.it/it/bvscorsi-batteria-per-la-valutazione-della-memoria-visiva-e-spaziale

Miller, H., \& Bichsel, J. (2004). Anxiety, working memory, gender, and math performance. Personality and Individual Differences, 37(3), 591-606. https://doi.org/10.1016/j.paid.2003.09.029

Miyake, A., Friedman, N. P., Rettinger, D. A., Shah, P., \& Hegarty, M. (2001). How are visuospatial working memory, executive functioning, and spatial abilities related? A latent-variable analysis. Journal of Experimental Psychology: General, 130(4), 621-640. https://doi.org/10.1037/0096-3445.130.4.621

Namkung, J. M., Peng, P., \& Lin, X. (2019). The relation between mathematics anxiety and mathematics performance among school-aged students: a meta-analysis. Review of Educational 
Research, 89(3), 459-496. https://doi.org/10.3102/0034654319 843494

Orsini, A., Pezzuti, L., \& Picone, L. (2012). WISC-IV. Contributo alla taratura italiana. Firenze, Italy. Giunti OS.

Owens, M., Stevenson, J., Hadwin, J. A., \& Norgate, R. (2012). Anxiety and depression in academic performance: An exploration of the mediating factors of worry and working memory. School Psychology International, 33(4), 433-449. https://doi.org/10.1177/ 0143034311427433

Passolunghi, M. C., \& Mammarella, I. C. (2010). Spatial and visual working memory ability in children with difficulties in arithmetic word problem solving. European Journal of Cognitive Psychology, 22(6), 944-963. https://doi.org/10.1080/09541440903091127

Passolunghi, M. C., \& Mammarella, I. C. (2012). Selective spatial working memory impairment in a group of children with mathematics learning disabilities and poor problem-solving skills. Journal of learning disabilities, 45(4), 341-350. https://doi.org/ 10.1177/0022219411400746

Passolunghi, M. C., \& Siegel, L. S. (2004). Working memory and access to numerical information in children with disability in mathematics. Journal of experimental child psychology, 88(4), 348-367. https://doi.org/10.1016/j.jecp.2004.04.002

Passolunghi, M. C., Cargnelutti, E., \& Pellizzoni, S. (2019). The relation between cognitive and emotional factors and arithmetic problem-solving. Educational Studies in Mathematics, 100(3), 271-290. https://doi.org/10.1007/s10649-018-9863-y

Passolunghi, M. C., De Vita, C., \& Pellizzoni, S. (2020). Math anxiety and math achievement: The effects of emotional and math strategy training. Developmental Science, e12964. https://doi.org/10. 1111/desc. 12964

Pekrun, R. (2006). The Control-Value Theory of Achievement Emotions: Assumptions, Corollaries, and Implications for Educational Research and Practice. Educ Psychol Rev, 18, 315-341. https:// doi.org/10.1007/s10648-006-9029-9

Pekrun, R., \& Perry, R. P. (2014). Control-value theory of achievement emotions. In International handbook of emotions in education (pp. 130-151). Routledge.

Pellizzoni, S., Apuzzo, G. M., De Vita, C., Agostini, T., Ambrosini, M., \& Passolunghi, M. C. (2020). Exploring EFs and math abilities in highly deprived contexts. Frontiers in psychology, 11, 383. https:// doi.org/10.3389/fpsyg.2020.00383

Ramirez, G., Gunderson, E. A., Levine, S. C., \& Beilock, S. L. (2013). Math anxiety, working memory, and math achievement in early elementary school. Journal of Cognition and Development, 14(2), 187-202. https://doi.org/10.1080/15248372.2012.664593

Reyna, V. F., Nelson, W. L., Han, P. K., \& Dieckmann, N. F. (2009). How numeracy influences risk comprehension and medical decision making. Psychological bulletin, 135(6), 943. https://doi.org/ $10.1037 / \mathrm{a} 0017327$
Rosseel, Y. (2012). Lavaan: An R package for structural equation modeling and more. Version 0.5-12 (BETA). Journal of statistical software, 48(2), 1-36. https://users.ugent.be/ yrosseel/lavaan/ lavaanIntroduction.pdf

Shah, P., \& Miyake, A. (1996). The separability of working memory resources for spatial thinking and language processing: An individual differences approach. Journal of experimental psychology: General, 125(1), 4. https://doi.org/10.1037/0096-3445.125.1.4

Soltanlou, M., Artemenko, C., Dresler, T., Fallgatter, A. J., Ehlis, A. C., \& Nuerk, H. C. (2019). Math anxiety in combination with low visuospatial memory impairs math learning in children. Frontiers in Psychology, 10, 89. https://doi.org/10.3389/fpsyg.2019.00089

Soltanlou, M., Pixner, S., \& Nuerk, H. C. (2015). Contribution of working memory in multiplication fact network in children may shift from verbal to visuo-spatial: a longitudinal investigation. Frontiers in psychology, 6, 1062. https://doi.org/10.3389/fpsyg.2015.01062

Swanson, H. L. (2008). Working memory and intelligence in children: What develops? Journal of Educational Psychology, 100(3), 581. https://doi.org/10.1037/0022-0663.100.3.581

Vukovic, R. K., Kieffer, M. J., Bailey, S. P., \& Harari, R. R. (2013). Mathematics anxiety in young children: Concurrent and longitudinal associations with mathematical performance. Contemporary educational psychology, 38(1), 1-10. https://doi.org/10.1016/j. cedpsych.2012.09.001

Weber, H. S., Lu, L., Shi, J., \& Spinath, F. M. (2013). The roles of cognitive and motivational predictors in explaining school achievement in elementary school. Learning and Individual Differences, 25, 85-92. https://doi.org/10.1016/j.lindif.2013.03.008

Wechsler, D. (2003). Wechsler Intelligence Scale for Children, (2003). San Antonia, TX: Psychological Corporation. https://doi.org/10. 1007/978-0-387-79061-9 3066

Wong, B., \& Szücs, D. (2013). Single-digit Arabic numbers do not automatically activate magnitude representations in adults or in children: Evidence from the symbolic same-different task. Acta Psychologica, 144(3), 488-498. https://doi.org/10.1016/j.actpsy. 2013.08.006

Wu, S. S., Willcutt, E. G., Escovar, E., \& Menon, V. (2014). Mathematics achievement and anxiety and their relation to internalizing and externalizing behaviors. Journal of learning disabilities, 47(6), 503-514. https://doi.org/10.1177/0022219412473154

Zhou, Z. (2011). Arithmetic Reasoning. In J. S. Kreutzer, J. DeLuca, \& B. Caplan (Eds.), Encyclopedia of Clinical Neuropsychology. Springer. https://doi.org/10.1007/978-0-387-79948-3_1434

Publisher's Note Springer Nature remains neutral with regard to jurisdictional claims in published maps and institutional affiliations. 